\title{
When the original is beyond reach: consumer perception and demand for counterfeit luxury goods in Germany and South Korea
}

\section{Nadine Hennigs*, Klaus-Peter Wiedmann, Christiane Klarmann and Stefan Behrens}

Institute of Marketing and Management,

Leibniz University of Hannover,

Germany

Email: hennigs@m2.uni-hannover.de

Email: wiedmann@m2.uni-hannover.de

Email:klarmann@m2.uni-hannover.de

Email: behrens@m2.uni-hannover.de

*Corresponding author

\section{Jaehee Jung}

Department of Fashion and Apparel Studies,

University of Delaware,

Newark, Delaware, USA

Email: jajung@udel.edu

\section{Choon Sup Hwang}

Department of Clothing and Textiles,

Kyung Hee University,

Seoul, South Korea

Email: cshwang@khu.ac.kr

\begin{abstract}
The tremendous growth in the luxury market in the last decades has been accompanied by a prevalence of pirated and counterfeit goods. Reasoning that all governmental efforts and management actions to curtail counterfeit activities will not be sufficient as long as counterfeiters face such an immense demand for their products, the importance of focusing on the consumer perspective becomes evident. In this context, the aim of this study is to provide and empirically investigate a comprehensive framework of the consumer demand for counterfeit luxury goods. Based on theoretical and empirical insights on the acceptance of counterfeits in different markets, we propose a model of determinants that influence the trade-off between genuine and counterfeit luxury goods from a consumer's perspective. The comparison of empirical data from Germany and South Korea reveal the significant impact of psychological and context-related antecedents on counterfeit perception and counterfeit shopping behaviour. The selected countries offer interesting insights in the consumer perspective on counterfeits as they provide distinct socio-cultural contexts and represent both the demand for authentic luxury brands as well as for counterfeit goods.
\end{abstract}


Keywords: luxury brands; counterfeit consumption; counterfeit risk perception; counterfeit shopping behaviour; Germany; South Korea; country comparison; anti-counterfeiting strategies.

Reference to this paper should be made as follows: Hennigs, N., Wiedmann, K-P., Klarmann, C., Behrens, S., Jung, J. and Hwang, C.S. (2015) 'When the original is beyond reach: consumer perception and demand for counterfeit luxury goods in Germany and South Korea', Luxury Research J., Vol. 1, No. 1, pp.58-75.

Biographical notes: Nadine Hennigs is an Assistant Professor at the Institute of Marketing and Management at Leibniz University of Hannover, Germany.

Klaus-Peter Wiedmann is the Director of the Institute of Marketing and Management at Leibniz University of Hannover, Germany.

Christiane Klarmann is a Scientific Assistant at the Institute of Marketing and Management at Leibniz University of Hannover, Germany.

Stefan Behrens is a Scientific Assistant at the Institute of Marketing and Management at Leibniz University of Hannover, Germany.

Jaehee Jung is an Associate Professor in the Department of Fashion and Apparel Studies at the University of Delaware, Newark, Delaware, USA.

Choon Sup Hwang is a Professor of Fashion Merchandising in the Department of Clothing and Textiles at the Kyung Hee University, Seoul, South Korea.

\section{Introduction}

In last decades, there has been an enormous theoretical as well as practical debate on concepts of consumer misbehaviour. This also included the purchase of counterfeit goods, due to the increasing economic importance of this illicit market. The continuous growth of the global market for luxury goods has been accompanied by a prevalence of pirated and counterfeit goods (Swami et al., 2009; Furnham and Valgeirsson, 2007). Over the last two decades, counterfeiting has increased substantially and today, the total global economic value of counterfeit and pirated products accounts for as much as $\$ 650$ billion every year and is estimated to be $\$ 1.77$ trillion in 2015 (International Chamber of Commerce (ICC)]. As these illicit goods can be found in almost every country in the world and all sectors of the global economy, the prevalence of pirated and counterfeit goods represents a significant and growing problem worldwide.

As the market for counterfeits is often related to organised crime and international terrorism, counterfeiting does not only harm the legitimate producers who have invested in research, product development, and marketing, but has also an impact on the economy, society and development (Furnham and Valgeirsson, 2007; Green and Smith, 2002). Nevertheless, most consumers disregard the negative effects counterfeiting entails (Phau et al., 2009). Even though successful countermeasures can just be developed based on a comprehensive understanding of the demand side, researchers claim that the investigation of this area of customer behaviour is deficient (de Matos et al., 2007; Swami et al., 2009), and the analysis of perceived values and risks as motivational drivers of this kind of 
consumer misbehaviour is still missing (Wiedmann et al., 2012). Against the backdrop of the increased global demand for counterfeit branded products, it is reasonable to study possible determinants of consumers' counterfeit purchase behaviour at an individual level but also across nations with different economic performance (Bian and Veloutsou, 2007; Phau and Teah, 2009).

To advance current understanding, based on a multidimensional framework proposed by Hennigs et al. (2012), the significant impact of psychological and context-related antecedents on counterfeit perception and counterfeit shopping behaviour will be presented with reference to a comparison of data from Europe (Germany) and Asia (South Korea). Particularly, one main research question will be investigated: Do similar perceptions of counterfeit products exist across countries, or are there significant differences in perceptions of counterfeit goods internationally? The results of our comparative study will be discussed regarding research and managerial implications as opportunities to develop distinct strategies for luxury brand managers that aim to reduce the global appetite for counterfeits addressing country-specific differences.

\section{Theoretical background}

\subsection{The concept of luxury and motives for luxury consumption}

The tremendous growth in the luxury market in last decades has been accompanied by a prevalence of pirated and counterfeit goods. Thus, in order to investigate the demand side of counterfeits, first of all, the concept of luxury should be clarified. Although the concept gained managerial as well as scientific relevance, a clear definition of luxury still does not exist. Grossman and Shapiro (1988, p.82) define luxury goods as "goods for which the mere use or display of a particular branded product confers prestige on their owners, apart from any utility deriving from their function". Recent research highlights the importance of the hedonic-oriented luxury consumption, apart from status-oriented luxury consumption. Thus, "the marketing of luxury goods has become increasingly complex, being associated not only with conveying an image of quality, performance and authenticity, but also with attempting to sell an experience by relating it to the lifestyle constructs of consumers" (Atwal and Williams, 2009). Accordingly, from a consumer perspective, with reference to Wiedmann et al. (2007, 2009), luxury brands can satisfy financial, functional, individual and social needs.

\subsection{Definition of deceptive and non-deceptive counterfeiting}

The focus of this study is on counterfeiting that can be defined as "...any manufacturing of a product which so closely imitates the appearance of the product of another to mislead a consumer that it is the product of another or deliberately offer a fake substitute to seek potential purchase from non-deceptive consumers" (OECD, 1998). According to this, it has to be distinguished between deceptive and non-deceptive counterfeit consumption (Grossman and Shapiro, 1988). Deceptive counterfeiting refers to copies where consumers cannot readily differentiate between copy and authentic product - and thus, the consumer can be regarded as a victim that unknowingly purchases a counterfeit product (Phau and Teah, 2009). Non-deceptive counterfeiting, on the other hand, is related to the situation when the consumer knows or strongly suspects that the purchased 
product is not an original (Grossman and Shapiro, 1988). Markets for automotive parts, pharmaceuticals and medical devices are often threatened by deceptive counterfeiting (Grossman and Shapiro, 1988), whereas non-deceptive counterfeiting is prevailing in the luxury market (Nia and Zaichkowsky, 2000). Talking about non-deceptive counterfeiting, customer complicity is often mentioned, as counterfeits are actively demanded (Chaudhry and Stumpf, 2011). Thus, the most promising way to defeat counterfeiting is to reduce the demand, which underlines the importance of investigating the antecedents of counterfeit consumption (Klarmann et al., 2013). Existing studies have investigated the consumer's attitudes to as well as underlying assumptions on counterfeit consumption. Wiedmann et al. (2012) argue that the trade-off between genuine and counterfeit is determined by the value of the original. Furthermore, they approved that the choice-process is significantly influenced by the risk perception in view of the faked product (Hennigs et al., 2012). Based on these insights, this study focuses on cultural differences in counterfeit consumption, comparing a European (Germany) and an Asian (South Korea) country. Both countries are flooded with counterfeit products that are very difficult for manufacturers and the local authorities to combat.

\subsection{Cultural differences in counterfeit consumption}

A comparison of Germany and South Korea representing Western and Asian industrialised economies with distinctive cultural differences might be of particular interest for the purposes of the present study. Germany has a long-standing tradition in the manufacturing and purchase of luxury brands, particularly in the luxury automobile and furniture segments. Measured by market size, the German luxury market belongs to the top three global luxury markets (Roland Berger, 2010). A study by Roland Berger (2013) confirmed the progressively growth of the German luxury market, related to consumers' demand for high quality, technological innovation and unique design. Germany is also of specific interest for the present study on counterfeiting, as German consumers have a particularly high exposure to counterfeit goods compared to other European countries: Following the Netherlands with Rotterdam as the biggest seaport in Europe, Germany with the second (Hamburg) and fourth (Bremen) largest ports detects the second largest volume of counterfeits entering the EU (European Commission, 2009; UNODC, 2010).

Similarly to Germany, South Korean consumer demand for top-quality and prestigious goods and unique design reveal positive growth in luxury goods consumption despite of increasing product prices. South Korea as part of the N-11 (introduced by Goldman and Sachs according to G-7 and BRIC), although classified as an emerging market in financial terms, is in most respects a very well developed economy and maturing market for luxury brands. The income levels are more than twice as high as any of the N-11 countries. South Korea has gone through drastic economic, social and cultural changes during the past four decades, which enabled rapid economic development with a large increase in GDP, urbanisation of the population ( $83 \%$ of total population), and consequently increasing consumer buying power. South Korea is the 3rd largest luxury goods market following Japan and China and the luxury goods market in South Korea continued to grow in 2013 despite of ongoing economic recession (http://www.euromonitor.com/luxury-goods-in-south-korea/report). With the declining luxury consumption in Japan for the past few years, many luxury brands are trying to seize the market demand in South Korea to compensate their loss in the Japanese market. 
Unlike Chinese consumers who like to purchase their luxury goods overseas making Chinese top global customers, Korean consumers purchase their luxury goods from domestic retailers (D'Arpizio, 2014). In fact, the Korean market is widely viewed as the fashion leader in Asia Pacific region and many Chineses tourists are willing indulge when visiting Korea (http://www.euromonitor.com/luxury-goods-in-south-korea/report). A number of luxury brands such as Louis Vuitton, Chanel, Cartier and Prada have flagship stores in main branches of the South Korea's top three department stores, Lotte, Hyundai and Shinsegae Department Stores, located in metropolitan cities such as Seoul, Busan, Incheon and Daegu. The recently opened first premium outlet store in Yeo-Ju where discounted luxury goods can be found has also gained unprecedented popularity.

Material display of luxury brands became an indication of the elite social class and the increased average disposable income of households resulted in a larger luxury goods consumer base. Many young people in Korea are addicted to luxury brands. It is not uncommon that younger consumers who cannot afford to buy authentic luxury brand bags would work part-time to purchase items equivalent to several months of salary. They may also choose to purchase counterfeit luxury bags as the counterfeit luxury market in Korea offers a wide variety of luxury goods associated with designer labels. In Korea, Louis Vuitton holds the unfortunate honour of being the most popular counterfeited luxury good brand because of its distinct and easily identifiable LV emblem canvas handbags. In Seoul, women are seen carrying the recognisable Louis Vuitton bag. The handbags appear to be real, however, are just extremely high quality counterfeits that are widely available to buy in the streets or through internet sites. According to the Korea Intellectual Property Office, there were a total of 21,454 counterfeit Louis Vuitton bags seized in 2011. Korea has a lot of counterfeit goods sold openly in popular shopping districts, and is known for designer products that are hardly distinguishable from original lines, so-called 'super fakes' made in Korea with such high quality. Intellectual property rights protection in Korea is still lagging behind developed countries. Even if the city's judicial police arrest anyone of suspicion of producing and selling counterfeit designer goods, it is not difficult to purchase imitations of Louis Vuitton and Chanel bags, Cartier watches, and Burberry accessories. While in Germany, most of the faked products are import products or bought by consumers, e.g., on holiday trips, South Korea is a major counterfeit manufacturing and consuming country.

A review of existing studies dedicated to examine the influence of culture on luxury and counterfeit consumption provide evidence for the existence of differences among nationalities, especially between Eastern and Western cultures (i.e., Li and $\mathrm{Su}, 2007$; Tsai, 2005; Veloutsou and Bian, 2008). With reference to the countries included in the present study, it can be stated that Germany and South Korea differ in terms of the cultural dimensions as suggested by Hofstede (2001), Hofstede et al. (2010), Inglehart and Welzel (2010) and House et al. (2004). According to this, Germany is an individualistic country with fairly low power distance, high masculinity and uncertainty avoidance. In contrast to this, South Korea is a more collectivist-oriented country with higher power distance and even higher uncertainty avoidance but lower masculinity than Germany. These cultural differences might have a significant influence related to the consumer's perceived counterfeit risk and actual counterfeit shopping behaviour. 


\section{Conceptual model}

In an attempt to better understand the antecedents and outcomes of counterfeit risk perception, in line with previous research focusing on the demand side of counterfeit goods (Ang et al., 2001; Huang et al., 2004), psychological consumer traits as well as context-related issues might be summarised in a single model. Inspired by the work of Hennigs et al. (2012), the conceptual framework presented in Figure 1, considers a combination of personality factors (i.e., variety seeking, personal integrity, moral judgement, and risk aversion) and context-related factors (i.e., luxury involvement, luxury value perception, and the trade-off between genuine and counterfeit luxury goods) as antecedents of consumers' risk perception toward counterfeits and actual counterfeit shopping behaviour.

Figure 1 The conceptual model

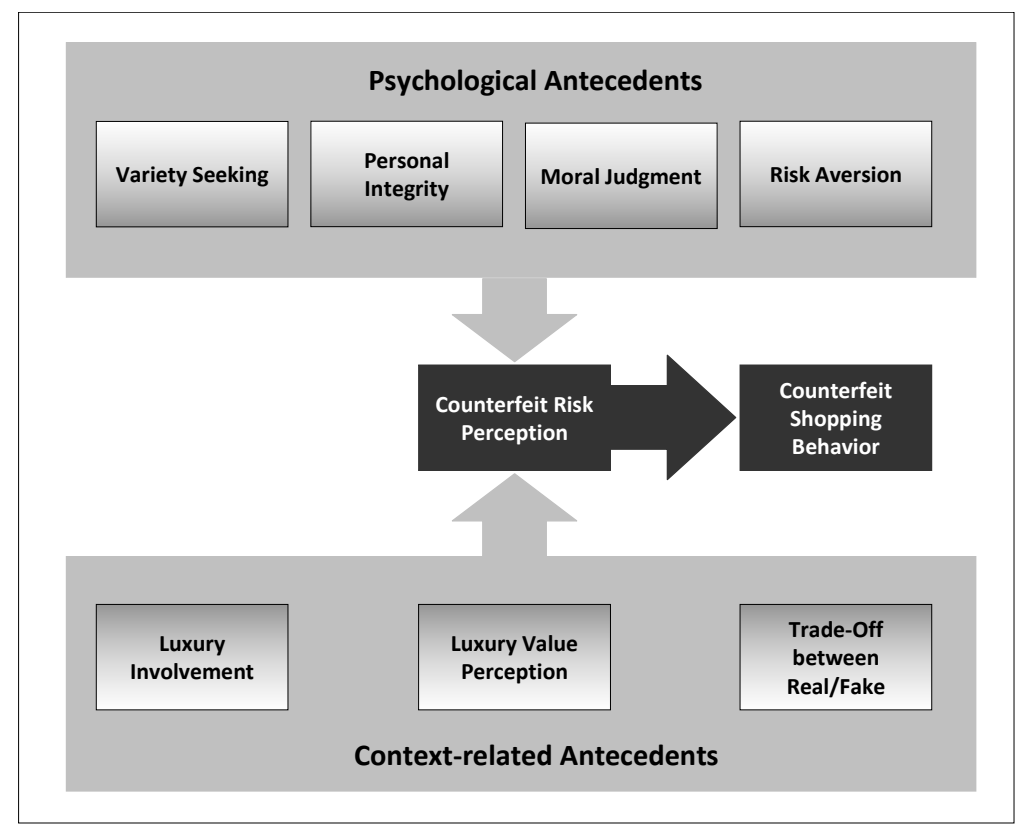

\subsection{Psychological antecedents}

- Variety seeking: Commonly, novelty seeking encompasses the desire of individuals to seek variety and difference (Phau and Teah, 2009; Wang et al., 2005), whereby especially the well-documented luxury characteristics of rarity and exclusivity (Vigneron and Johnson, 2004) may be connected to the consumer perceived variety. On the other hand, with reference to consumers who fear the hassle of being stuck with a 'last-season' item (Wiedmann et al., 2007), luxury counterfeits as mass products which are often out of season won't be convenient to a high variety seeking consumer. 
- Personal integrity: According to Michaelidou and Christodoulides (2011), who state that ethical obligation is different from personal integrity, consumers may value honesty, politeness and responsibility (de Matos et al., 2007). Thus, consumers do not inevitably feel obligated to avoid ethically questionable behaviours such as buying counterfeit products (Michaelidou and Christodoulides, 2011).

- Moral judgement: The moral judgement allows an individual to judge how far certain actions might be perceived as morally acceptable (Tan, 2002). In line with this, it can be supposed that consumers with a high standard of moral judgement may perceive a higher risk associated with counterfeit consumption because the counterfeit business is often related to organised crime (Furnham and Valgeirsson, 2007; Green and Smith, 2002; Nill and Schultz, 1996).

- Risk aversion: Defined as the propensity to avoid taking risks (Zinkhan and Karande, 1991), risk aversion can be seen as an important characteristic for discriminating between buyers and non-buyers of a certain product category (de Matos et al., 2007). Huang et al. (2004) already revealed a significant inverse relationship between risk averseness and attitude toward counterfeits.

\subsection{Context-related antecedents}

- Luxury involvement: Understood as an internal state that indicates the amount of arousal or interest, the involvement construct has been shown to be a strong predictor of purchase in general and related to selected product categories (Richins and Bloch, 1986; Dholakia, 2001). Consequently, a high level of product-class involvement leads to the consumer's willingness to spend more energy on consumption-related activities so that consumers with high luxury involvement have a more favourable attitude to luxury goods (Wilkie, 1994; Zaichkowsky, 1985).

- Luxury value perception: The question of what really adds value in consumer luxury perception can be explained by four dimensions (Wiedmann et al., 2007, 2009):

1 the financial dimension that addresses direct monetary aspects

2 the functional dimension that refers to basic utilities as quality, uniqueness, and usability

3 the individual dimension that addresses personal matters such as materialism, hedonism, and self-identity

4 the social dimension that refers to aspects of status consumption and prestige orientation.

With reference to counterfeit luxury goods, it is expected that consumers who have a high value perception of genuine luxury goods are less willing to purchase counterfeits (Wiedmann et al., 2012).

- $\quad$ Trade-off between genuine and counterfeit luxury goods: The market for counterfeit brands relies mainly on consumers' desire for and evaluation of real luxury brands (Hoe et al., 2003; Penz and Stöttinger, 2005). Hence, the individual choice decision between authentic and counterfeit products is influenced by a trade-off based on the 
combination of the price of the product (Furnham and Valgeirsson, 2007), the perceived value of the product (Bloch et al., 1993; Furnham and Valgeirsson, 2007), and the quality of the authentic product (Munshaw-Bajaj and Steel, 2010).

\subsection{Related outcomes}

- Counterfeit risk perception and counterfeit shopping behaviour. In addition to any potential values and benefits consumers may experience feelings of risk during the purchase decision process (Ha and Lennon, 2006). Understood as "the consumer's perceptions of the uncertainty and adverse consequences of buying a product or service" [Dowling and Staelin, (1994), p.119], consumers associate counterfeits with a higher level of risks that mediate consumers' feelings toward counterfeit purchases (Bamossy and Scammon, 1985; Chakraborty et al., 1996). It can be said that the perception of financial, functional, psychological, and social risks related to the purchase of a counterfeit good will influence every stage of the consumer decision-making process (de Matos et al., 2007).

As pointed out in the introduction, the growth of the global market for luxury goods has been accompanied by a rising demand for counterfeit branded products. Against the backdrop of the serious negative effects of counterfeiting for economies worldwide and due to the fact that successful countermeasures require a holistic understanding of the consumer perspective, it is crucial to study possible determinants of consumers' counterfeit purchase behaviour at an individual level but also across nations. Drawing from prior findings in cultural studies and based on our conceptual framework, one main research question will be analysed by using a cross-national data set which allows comparisons between the emerging South Korean and the already well-established German market:

- $R Q$ : Do similar perceptions of counterfeit products exist across countries, or are there significant differences in perceptions of counterfeit goods internationally?

Based on this, with reference to Clark's (1990) general hypothesis that is often used in cross-national studies, we formulate:

$\mathrm{H}_{0}$ Consumers in different countries exhibit the same perceptions of counterfeit goods.

$\mathrm{H}_{1}$ Consumers in different countries exhibit differing perceptions of counterfeit goods.

\section{Methodology}

To measure the antecedents and behavioural outcomes of counterfeit risk perception across countries based on our conceptual model and related hypotheses, we relied on existing and tested measures as shown in Table 1, that have been validated by Hennigs et al. (2012). All items were rated on five-point Likert scales $(1=$ strongly disagree to 5 = strongly agree). 
Table 1 The questionnaire scales

\begin{tabular}{ll}
\hline Scale & Author(s), year \\
\hline Psychological antecedents & \\
\hline Variety seeking & Donthu and Gilliland (1996) \\
Personal integrity & Ang et al. (2001) \\
Moral judgement & Tan (2002) \\
Risk aversion & Donthu and Gilliland (1996) \\
\hline Context-related antecedents & \\
\hline Luxury involvement & Beatty and Talpade (1994) \\
Luxury value perception & Sweeney and Soutar (2001) and Wiedmann et al. (2009) \\
Trade-off between genuine and & In accordance to Wiedmann et al. (2009) \\
counterfeit good & \\
\hline Related outcomes & Ang et al. (2001), Ha and Lennon (2006), and Stone and \\
\hline Counterfeit risk perception & Grønhaug (1993) \\
Counterfeit shopping behaviour & Kressmann et al. (2003) \\
\hline
\end{tabular}

As stated above, this study specifically focused on a comparison of South Korean and German consumers as South Korea is one of the maturing Asian countries with a ravenous appetite for luxury and counterfeits and, compared to other European countries, Germany has a top three position in global luxury markets and suffers from a particularly high exposure to counterfeit goods. The questionnaire was pre-tested with 20 respondents in each country. To address the issue of social desirability bias and the respondent's inclination to conform to social norms, we preferred purposive sampling for which the units of observation are habitually luxury and/or counterfeit consumers. The recruitment of interviewees was organised by a personal invitation mail that was sent to members of a luxury consumer panel. In the final sample, only those respondents were included who agreed to the statements that they are highly interested in the domain of luxury products and purchase luxury brands on a regular basis - either the original or the counterfeit alternative. Besides, all respondents in the final sample stated that they will purchase luxury brands again in the future. A total of 289 valid questionnaires (167 in South Korea, 122 in Germany) were received in January 2013. The sample characteristics are described in Table 2.

Table 2 Demographic profile of the sample

\begin{tabular}{|c|c|c|c|c|c|}
\hline \multirow{2}{*}{ Variable } & & \multicolumn{2}{|c|}{ South Korea } & \multicolumn{2}{|c|}{ Germany } \\
\hline & & $n$ & $\%$ & $n$ & $\%$ \\
\hline \multirow[t]{4}{*}{ Age } & $18-25$ years & 159 & 95.2 & 85 & 71.4 \\
\hline & $26-35$ years & 8 & 4.8 & 27 & 22.7 \\
\hline & $36-55$ years & 0 & 0 & 6 & 5.1 \\
\hline & 56-99 years & 0 & 0 & 1 & .8 \\
\hline \multirow[t]{2}{*}{ Gender } & Male & 27 & 16,2 & 46 & 37.7 \\
\hline & Female & 140 & 83.8 & 74 & 60.7 \\
\hline
\end{tabular}


Table 2 Demographic profile of the sample (continued)

\begin{tabular}{|c|c|c|c|c|c|}
\hline \multirow{2}{*}{ Variable } & & \multicolumn{2}{|c|}{ South Korea } & \multicolumn{2}{|c|}{ Germany } \\
\hline & & $n$ & $\%$ & $n$ & $\%$ \\
\hline \multirow[t]{3}{*}{ Marital status } & Single & 165 & 98.8 & 108 & 88.5 \\
\hline & Married & 1 & .6 & 11 & 9.0 \\
\hline & Widowed & 1 & .6 & 1 & .8 \\
\hline \multirow[t]{5}{*}{ Income } & Very low income & 1 & .6 & 3 & 2.5 \\
\hline & Low income & 27 & 16.2 & 7 & 5.7 \\
\hline & Middle income & 131 & 78.4 & 68 & 55.7 \\
\hline & High income & 8 & 4.8 & 36 & 29.5 \\
\hline & Very high income & 0 & 0 & 1 & .8 \\
\hline
\end{tabular}

In both countries, respondents mainly aged 18-25 are over-represented; the higher percentage of younger and female consumers may be attributed to the higher interest of female consumers in luxury brands and their willingness to participate in a study on luxury and counterfeit goods. Due to budget restrictions and the question of affordability of genuine luxury, it can be assumed that this consumer group is more likely to choose the counterfeit alternative of a luxury good (Yoo and Lee, 2009). Therefore, even if this sample is not representative for the German and Korean population, with reference to our research focus, it offers a balanced set of data from each country to empirically investigate consumer perceptions of counterfeit products based on a cross-cultural database. Referring to our study context, $16.8 \%$ of the Korean consumers and even $56.6 \%$ of the German consumers confess that they have bought a counterfeit luxury product at least once. In Germany, $19.7 \%$ of the respondents buy counterfeits on a regular basis (Korea: $4.2 \%$ ) and $29.5 \%$ consider buying counterfeit luxury goods in the future (Korea: $4.8 \%$ ). In contrast to this, $61.7 \%$ of the Korean consumers intend to buy genuine luxury goods in the future (Germany: $24.6 \%$ ).

\section{Results and discussion}

To examine possible differences and/or similarities across countries within the data analysis using SPSS 19.0, we first identified the various antecedents and behavioural outcomes of counterfeit risk perception through a factor analysis using the principal component method with varimax rotation. Based on the factor scores for each country, we used analysis of variance (ANOVA) to determine whether there are significant differences across countries in the psychological and context-related antecedents as well as behavioural outcomes. The results of the measurement of the constructs and the ANOVA results are described below.

\subsection{Measurement of constructs}

A cross-culturally applicable measurement instrument should lead to similar patterns of reliability, factor loadings, and factor structure in samples from different countries. As Table 3 shows the factor structure of our cross-national database largely confirms the insights of Hennigs et al. (2012) and our proposed conceptualisation. 
Table 3 Measurement of constructs

\begin{tabular}{lc}
\hline \multicolumn{1}{c}{ Items } & Fsychological antecedents \\
\hline F1 Variety seeking & Cronbach's $\alpha=.834$ \\
\hline I like to try different things. & .862 \\
I like a great deal of variety. & .908 \\
I like new and different styles. & .838 \\
\hline F2 Personal integrity & Cronbach's $\alpha=.688$ \\
\hline I consider honesty an important human trait. & .797 \\
I consider politeness an important human trait. & .796 \\
I consider responsibility an important human trait. & .766 \\
\hline F3 Moral judgement & Cronbach's $\alpha=.890$ \\
\hline In my opinion, it is morally wrong to buy a counterfeit instead of the & .915 \\
genuine product. & .948 \\
It is morally wrong to buy counterfeit luxury goods. & .852 \\
There are ethical reasons against buying counterfeit luxury products. & .739 \\
\hline F4 Risk aversion & Cronbach's $\alpha=.697$ \\
\hline I would rather be safe than sorry. & .797 \\
I want to be sure before I purchase anything. & .833 \\
I avoid risky things. &
\end{tabular}

I avoid risky things.

\begin{tabular}{lc}
\hline \multicolumn{2}{c}{ Context-related antecedents } \\
\hline F5 Luxury involvement & Cronbach's $\alpha=.700$ \\
\hline I am very interested in luxury goods. & .866 \\
Luxury goods play an important role in my life. & .874 \\
I never get bored when people talk about luxury goods. & .633 \\
\hline F6 Luxury value perception & Cronbach's $\alpha=.752$ \\
\hline The price of a luxury good matches its quality. & .653 \\
Luxury products are made of high quality. & .680 \\
A luxury good satisfies my needs. & .717 \\
A luxury product cannot be sold in supermarkets. & .528 \\
The luxury brands I buy must match what and who I really am. & .238 \\
For me luxury goods are truly delightful. & .599 \\
I like a lot of luxury in my life. & .656 \\
I like to know what brands and products make a good impression on & .496 \\
others. & .648 \\
Luxury goods help to make a good impression on others. & \\
\hline
\end{tabular}


Table 3 Measurement of constructs (continued)

\begin{tabular}{|c|c|}
\hline Items & Factor loadings \\
\hline \multicolumn{2}{|l|}{ Context-related antecedents } \\
\hline F7 Trade-off between genuine and counterfeit goods referring to... & Cronbach's $\alpha=.825$ \\
\hline Functionality & .502 \\
\hline Quality & .679 \\
\hline Usability & .531 \\
\hline Uniqueness & .495 \\
\hline Prestige & .592 \\
\hline My self-concept & .646 \\
\hline Personal gratification & .728 \\
\hline Visual attributes: logo and brand insignia & .516 \\
\hline Conspicuousness & .426 \\
\hline Social status & .617 \\
\hline Self-realisation & .643 \\
\hline Belonging to friends & .513 \\
\hline Ethical aspects & .522 \\
\hline \multicolumn{2}{|l|}{ Related outcomes } \\
\hline F8 Counterfeit risk perception & Cronbach's $\alpha=.731$ \\
\hline $\begin{array}{l}\text { If I bought a counterfeit luxury product, I would be concerned that I } \\
\text { really would not get my money's worth from this product. }\end{array}$ & .707 \\
\hline The quality of a fake product will be very poor. & .461 \\
\hline I would not feel very comfortable wearing a fake product in public. & .804 \\
\hline $\begin{array}{l}\text { People in my social environment do not appreciate counterfeit luxury } \\
\text { goods. }\end{array}$ & .676 \\
\hline All in all, I consider buying a counterfeit luxury product as very risky. & .793 \\
\hline F9 Counterfeit shopping behaviour & Cronbach's $\alpha=.736$ \\
\hline I have already bought counterfeit luxury products. & .795 \\
\hline I have bought counterfeit luxury products several times. & .870 \\
\hline I consider buying counterfeit luxury goods in the future. & .775 \\
\hline I do not intend to buy genuine luxury goods in the future. & .584 \\
\hline
\end{tabular}

\subsection{Cross-national comparison}

ANOVA was used to explore possible cross-national differences between the Korean and German counterfeit risk perception and shopping behaviour. For this purpose, the country was the independent (grouping) variable and the factors that were identified against the backdrop of our conceptual model were the dependent variables (factor mean scores). As presented in Table 4, our research hypothesis $\mathrm{H}_{1}$ can be confirmed because the participants differed significantly $(\mathrm{p}<.01)$ in the degree to which they agreed with the statements related to the psychological and context-related antecedents as well as 
behavioural outcomes. Figure 2 is a graphical representation of the values for each country.

Table 4 ANOVA results

\begin{tabular}{lcc}
\hline Psychological antecedents & $F$ & Sig \\
\hline F1 Variety seeking & 7.157 & .008 \\
F2 Personal integrity & 27.349 & .000 \\
F3 Moral judgement & .067 & .796 \\
F4 Risk aversion & 10.446 & .001 \\
\hline Context-related antecedents & & .006 \\
\hline F5 Luxury involvement & 7.577 & .236 \\
F6 $\quad$ Luxury value perception & 1.409 & .454 \\
F7 $\quad$ Trade-off between genuine and counterfeit goods & .563 & \\
\hline Related outcomes & & .087 \\
\hline F8 $\quad$ Counterfeit risk perception & 2.951 & .000 \\
\hline F9 $\quad$ Counterfeit shopping behaviour & 136.628 & \\
\hline
\end{tabular}

Figure 2 Cross-national counterfeit risk perception and shopping behaviour (see online version for colours)

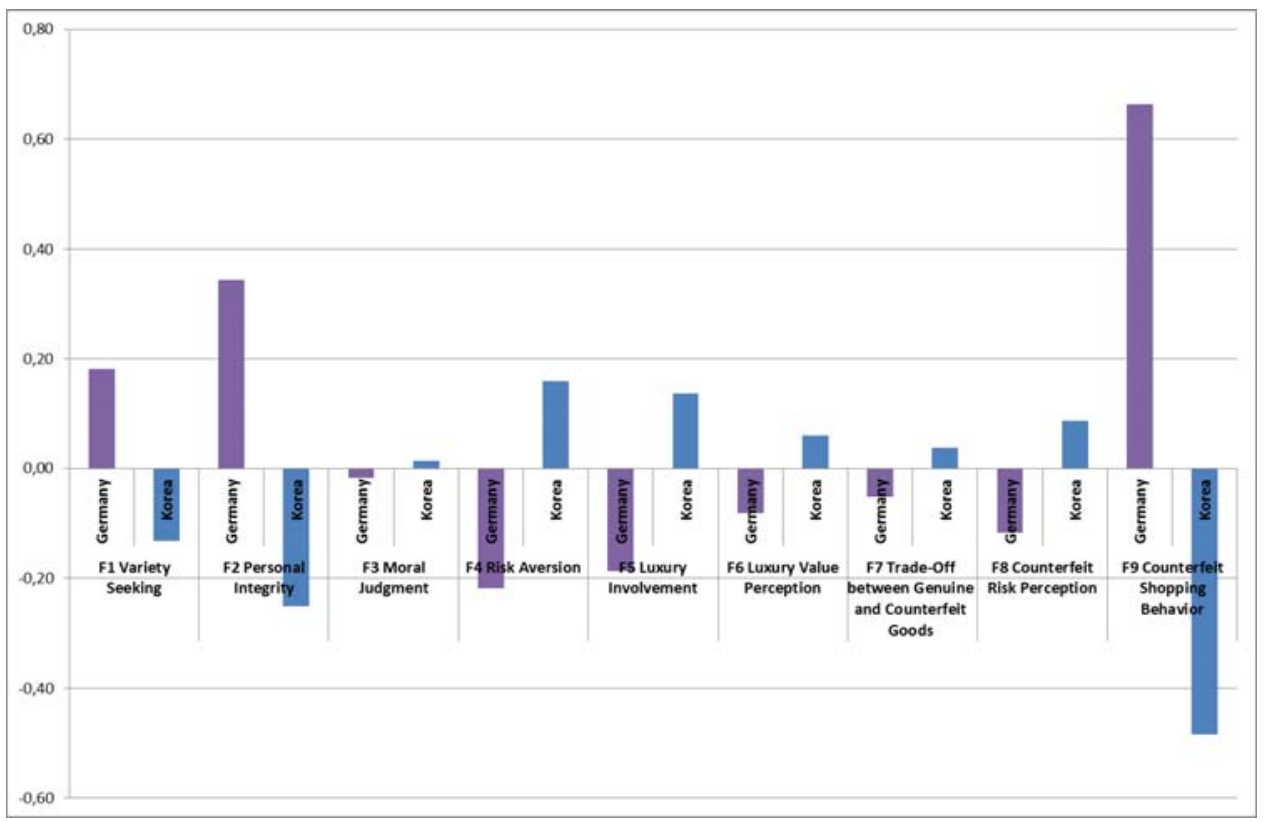


With reference to the psychological antecedents, the results show that Korean and German consumers differ mainly in their perception of statements related to personal integrity, risk aversion and variety seeking. More than Korean respondents, Germans state that honesty, politeness, and responsibility are important human traits and agree that "there are ethical reasons against buying counterfeit luxury products". Besides, German consumers are more inclined to try different things and like a great deal of variety, whereas Koreans tend to be more risk-averse: They agree that they "would rather be safe than sorry" and "avoid risky things".

Considering the context-related antecedents, Korean consumers are more than consumers in Germany personally interested and highly involved in the domain of luxury. In particular, Koreans approve the statements referring to the social and status-related aspects of luxury: They "like to know what brands and products make a good impression on others" and prefer luxury brands that "match what and who I really am" and "help to make a good impression on others". Against this backdrop, judging a trade-off between genuine and counterfeit goods, Korean consumers admit a slightly stronger preference for the counterfeit alternative than Germans, however, certainly not in terms of aspects such as conspicuousness, prestige and social status. Given that they are concerned about what others think of them and fear negative social consequences, Koreans clearly prefer the genuine luxury product, whereas Germans attach more importance to functional attributes of the authentic product such as quality, uniqueness, and usability.

In terms of behavioural outcomes, the results reveal significant differences in the perception of Korean and German consumers to aspects of counterfeit risk perception and actual shopping behaviour. Again, Korean consumers emphasise the social aspects of luxury consumption: More than Germans, they consider buying a counterfeit luxury product as very risky and "would not feel very comfortable wearing a fake product in public" because they are afraid that "people in my social environment do not appreciate counterfeit luxury goods". In contrast, German consumers more agree with performance-related statements such as "if I bought a counterfeit luxury product, I would be concerned that I really would not get my money's worth from this product" or "the quality of a fake product will be very poor". Besides, the results clearly show that Germans are significantly more likely than Koreans to confess that they have already bought counterfeit products and consider buying counterfeit luxury goods in the future. Reasoning the social consciousness of Korean consumers as stated above, one might assume that their answers to the behavioural statements might be influenced by socially desirable response patterns.

In sum, with regard to our initial research question and hypotheses, supportive of $H_{l}$, the ANOVA results provide evidence to confirm significant cross-national differences between the antecedents and behavioural outcomes of counterfeit risk perception as perceived by consumers from South Korea and Germany. Hence, the perception and consumption of counterfeit luxury goods are multifaceted and comprise a combination of aspects whose importance differs across countries. Reasoning this, the question arises of the optimal basis on which appropriate marketing strategies should be developed in the luxury industry to effectively fight against the rising global appetite for counterfeits. For that reason, the following paragraph discusses possible implications for future research and managerial practice that can be derived from our study insights. 


\section{Conclusions}

Against the backdrop of the tremendous growth in the luxury market along with an increased demand for counterfeit branded products, research on specific factors that significantly influence counterfeit perception and counterfeit shopping behaviour in diverse markets has gained importance. In this context, the aim of this study was to provide and empirically investigate a comprehensive framework of the consumer demand for counterfeit luxury goods. Based on theoretical and empirical insights on the acceptance of counterfeits in different markets, we proposed a model of determinants that influence the trade-off between genuine and counterfeit luxury goods from a consumer's perspective. The comparison of empirical data from Europe (Germany) and Asia (South Korea) revealed the significant impact of psychological and context-related antecedents on counterfeit perception and counterfeit shopping behaviour. It has to be noted that the sample used in this study is not a representative one and due to the limited generalisability of the results, it is reasonable to replicate the study with a large sample of typical luxury (counterfeit) consumers in both countries to gain more differentiated results. Nevertheless, the selected countries offered interesting insights in the consumer perspective on counterfeits as they provide distinct socio-cultural contexts and represent both the demand for authentic luxury brands as well as for counterfeit goods. In detail, the results give evidence that Korea's collectivism and high level of public consciousness leads consumers to purchase genuine luxury brands, however, those who cannot afford the authentic products try to buy counterfeit items that would be difficult to identify as fakes, based on the high quality of the counterfeit goods. In contrast to this, German consumers mainly associate luxury goods with superior functional value and tend to be risk-averse in the context of the performance and quality of counterfeits. Nevertheless, Germans are more likely than Koreans to confess that they are regular buyers of counterfeit goods. This might be due to the fact that South Korea is strongly influenced by Confucian values and consumers attach great importance to social pressures of group conformity and face-saving (Lee and Green, 1991). Therefore, as our results underline, to preserve their reputation and status, Koreans state that they prefer to purchase products and brands that match their social position.

From a managerial perspective, our comparative study may form an appropriate basis to develop distinct strategies that aim to reduce the global appetite for counterfeits addressing country-specific differences. The results indicate that countermeasures focusing on the price only - a determinant that is often believed to be the main reason that causes counterfeit purchases - falls short. Our study reveals that there are multifaceted reasons that affect consumer attitudes and behaviour; moreover the combination of psychological and context-related antecedents affecting counterfeit risk perception and shopping behaviour was shown to vary between countries. Therefore, the key challenge is to identify and address the specific risks and responsibilities associated with counterfeit consumption that are perceived by distinct consumer groups as the most important barriers against counterfeit shopping. In our research context, German consumers refrain from the low performance and quality of counterfeits, whereas Koreans worry about social consequences that might comprise their reputation. With regard to possible directions for future research, qualitative experiments and quantitative analyses should further examine both the reasons why consumers choose the counterfeit over the authentic product and consumers responses to specific anti-counterfeit campaigns and activities. 
In sum, only a holistic approach and joint efforts encompassing detailed research on the consumer demand side as well as combined activities by governments, supranational organisations, and industry associations have the potential to curtail the illegitimate business of worldwide counterfeiting.

\section{Acknowledgements}

The authors would like to thank the editor, Prof. Michel Phan, and the anonymous reviewers for their valuable comments and constructive suggestions.

\section{References}

Ang, S.H., Cheng, P.S., Lim, E.A.C. and Tambyah, S.K. (2001) 'Spot the difference: consumer responses towards counterfeits', Journal of Consumer Marketing, Vol. 18, No. 3, pp.219-235.

Atwal, G., and Williams, A. (2009) 'Luxury brand marketing - the experience is everything!', Journal of Brand Management, Vol. 16, No. 5, pp.338-346.

Bamossy, G. and Scammon, D.L. (1985) 'Product counterfeiting: consumers and manufacturers beware', Advances in Consumer Research, Vol. 12, No. 1, pp.334-340.

Beatty, S.E. and Talpade, S. (1994) 'Adolescent influence in family decision making: a replication with extension', Journal of Consumer Research, Vol. 21, No. 2, pp.332-341.

Bian, X. and Veloutsou, C. (2007) 'Consumers' attitudes regarding non-deceptive counterfeit brands in the UK and China', Journal of Brand Management, Vol. 14, No. 3, pp.211-222.

Bloch, P.H., Bush, R.F. and Campbell, L. (1993) 'Consumer 'accomplices' in product counterfeiting: a demand side investigation', Journal of Consumer Marketing, Vol. 10, No. 4, pp.27-36.

Chakraborty, G., Allred, A.T. and Bristol, T. (1996) 'Exploring consumers' evaluations of counterfeits: the roles of country of origin and ethnocentrism', Advances in Consumer Research, Vol. 23, pp.379-384.

Chaudhry, P. and Stumpf, S. (2011) 'Consumer complicity with counterfeit products', Journal of Consumer Marketing, Vol. 28, No. 2, pp.139-151.

Clark, T. (1990) 'International marketing and national character: a review and proposal for an integrative theory', Journal of Marketing, Vol. 54, No. 4, pp.66-79.

D’Arpizio, C. (2014) 'Luxury goods worldwide market study spring 2014' [online] http://www.bain.com/publications/articles/ luxury-goods-worldwide-market-study-spring-2014.aspx (accessed 15 September 2014).

de Matos, C., Augusto, C., Ituassu, T. and Rossi, C.A.V. (2007) 'Consumer attitudes toward counterfeits: a review and extension', Journal of Consumer Marketing, Vol. 24, No. 1, pp.36-47.

Dholakia, U.M. (2001) 'A motivational process model of product involvement and consumer risk perception', European Journal of Marketing, Vol. 33, No. 11, pp.1340-1362.

Donthu, N. and Gilliland, D. (1996) 'The informercial shopper', Journal of Advertising Research, Vol. 36, No. 2, pp.69-76.

Dowling, G.R. and Staelin, R. (1994) 'Model of perceived risk and intended risk-handling activity', Journal of Consumer Research, Vol. 21, No. 1, pp.119-134.

Euromonitor International, Luxury Goods in South Korea [online] $\mathrm{http}: / /$ www.euromonitor.com/luxury-goods-in-south-korea/report (accessed 15 September 2014).

European Commission (2009) Report on EU Customs Enforcement of Intellectual Property Rights, Results at the European Border - 2008, European Commission, Brussels. 
Furnham, A. and Valgeirsson, H. (2007) 'The effect of life values and materialism on buying counterfeit products', The Journal of Socio-Economics, Vol. 36, No. 5, pp.677-685.

Green, R.T. and Smith, T. (2002) 'Countering brand counterfeiters', Journal of International Marketing, Vol. 10, No. 4, pp.89-106.

Grossman, G.M. and Shapiro, C. (1988) 'Foreign counterfeiting of status goods', The Quarterly Journal of Economics, Vol. 103, No. 1, pp.79-100.

Ha, S. and Lennon, S. (2006) 'Purchase intent for fashion counterfeit products: ethical ideologies, ethical judgments, and perceived risks', Clothing and Textiles Research Journal, Vol. 4, No. 4, pp.297-315.

Hennigs, N., Klarmann, C. and Wiedmann, K-P. (2012) 'Because you're worth it? Consumers' risk perception in the trade-off between genuine and counterfeit luxury goods', in Lee, S.H. (Ed.): Globalization and Marketing Performance. Proceedings of the 2012 Global Marketing Conference, Seoul, 19-22 July, $2371 \mathrm{ff}$.

Hoe, L., Hogg, G. and Hart, S. (2003) 'Fakin' it: counterfeiting and consumer contradictions', European Advances in Consumer Research, Vol. 6, pp.60-67.

Hofstede, G. (2001) Culture's Consequences: Comparing Values, Behaviors, Institutions And Organizations Across Nations, Sage Publications, Newbury Park.

Hofstede, G., Hofstede, G.J. and Minkov, M. (2010) Cultures and Organizations: Software of the Mind, 3rd ed., McGraw-Hill, New York, NY.

House, R.J., Hanges, P.J., Javidan, M., Dorfman, P.W. and Gupta, V. (Eds.) (2004) Culture, Leadership and Organizations: The GLOBE Study of 62 Societies, Thousand Oaks, CA, Sage Publications.

Huang, J.H., Lee, B.C.Y. and Hoe, S.H. (2004) 'Consumer attitude toward gray market goods', International Marketing Review, Vol. 21, No. 6, pp.598-614.

Inglehart, R. and Welzel, C. (2010) 'Changing mass priorities: the link between modernization and democracy', Perspectives on Politics, Vol. 8, No. 2, pp.551-567.

Klarmann, C., Wiedmann, K-P. and Hennigs, N. (2013) 'Luxury longing and counterfeit complicity: a consumer typology based on the perception of luxury value and counterfeit risk', in Wiedmann, K-P. and Hennigs, N. (Eds.): Luxury Marketing, pp.261-277, Wiesbaden.

Kressmann, F., Herrmann, A., Huber, F. and Magin, S. (2003) 'Dimensionen der Markeneinstellung und ihre Wirkung auf die Kaufabsicht', Die Betriebswirtschaft, Vol. 63, No. 4, pp.401-418.

Lee, C. and Green, R.T. (1991) 'Cross-cultural examination of the Fishbein behavioral intentions model', Journal of International Business Studies, Vol. 22, No. 2, pp.289-305.

Li, J.J. and Su, C. (2007) 'How face influences consumption: a comparative study of American and Chinese consumers', International Journal of Market Research, Vol. 49, No. 2, p.237.

Michaelidou, N. and Christodoulides, G. (2011) 'Antecedents of attitude and intention towards counterfeit', Journal of Marketing Management, Vol. 27, Nos. 9-10, pp.976-991.

Munshaw-Bajaj, N. and Steel, M. (2010) Exploring Consumer Choices in Shopping for Authentic and Counterfeit Goods [online] http://anzmac2010.org/proceedings/pdf/anzmac10 final00149.pdf (accessed 23 April 2013).

Nia, A. and Zaichkowsky, J.L. (2000) 'Do counterfeits devalue the ownership of luxury brands?', Journal of Product \& Brand Management, Vol. 9, No. 7, pp.485-497.

Nill, A. and Shultz, C.J. (1996) 'The scourge of global counterfeiting', Business Horizons, Vol. 39, No. 6, pp.37-42.

OECD (1998) The Economic Impact of Counterfeiting [online] http://www.oecd.org/dataoecd/11/11/2090589.pdf (accessed 23 July 2010).

Penz, E. and Stöttinger, B. (2005) 'Forget the real thing-take the copy! An explanatory model for the volitional purchase of counterfeit products', Advances in Consumer Research, Vol. 32, pp.568-575. 
Phau I., Sequeira, M. and Dix, S. (2009) 'Consumers' willingness to knowingly purchase counterfeit products', Direct Marketing: An International Journal, Vol. 3, No. 4, pp.262-281.

Phau, I. and Teah, M. (2009) 'Devil wears (counterfeit) Prada: a study of antecedents and outcomes of attitudes towards counterfeits of luxury brands', Journal of Consumer Marketing, Vol. 26, No. 1, pp.15-27.

Richins, M.L. and Bloch, P.H. (1986) 'The temporal context of product involvement', Journal of Consumer Research, Vol. 13, No. 2, pp.280-285.

Roland Berger (2013) Meisterkreis Index 2013 [online] http://www.rolandberger.com/media/pdf/Roland_Berger_Meisterkreis_Luxus_Index_2013022 5.pdf (accessed 23 April 2013).

Stone, R.N. and Grønhaug, K. (1993) 'Perceived risk: further considerations for the marketing discipline', European Journal of Marketing, Vol. 27, No. 3, pp.39-50.

Swami, V., Chamorro-Premuzic, T. and Furnham, A. (2009) 'Faking it: personality and individual difference predictors of willingness to buy counterfeit goods', The Journal of SocioEconomics, Vol. 38, No. 5, pp.820-825.

Sweeney, J.C. and Soutar, G.N. (2001) 'Consumer perceived value: the development of a multiple item scale', Journal of Retailing, Vol. 77, No. 2, pp.203-220.

Tan, B. (2002) 'Understanding consumer ethical decision making with respect to purchase of pirated software', Journal of Consumer Marketing, Vol. 19, No. 2, pp.96-111.

Tsai, S.P. (2005) 'Impact of personal orientation on luxury-brand purchase value', International Journal of Market Research, Vol. 47, No. 4, pp.429-454.

United Nations Office on Drugs and Crime (UNODC) (2010) The Globalization of Crime: A Transnational Organized Crime Threat Assessment, UNODC, Vienna.

Veloutsou, C. and Bian, X. (2008) 'A cross-national examination of consumer preceived risk in the context of non-deceptive counterfeit brands', Journal of Consumer Behaviour, Vol. 7, No. 1, pp.3-20.

Vigneron, F. and Johnson, L.W. (2004) 'Measuring perceptions of brand luxury', Journal of Brand Management, Vol. 11, No. 6, pp.484-506.

Wang, F., Zhang, H., Zang, H. and Ouyang, M. (2005) 'Purchasing pirated software: an initial examination of Chinese consumers', Journal of Consumer Marketing, Vol. 22, No. 6, pp.340-351.

Wiedmann, K-P., Hennigs, N. and Klarmann, C. (2012) 'Luxury consumption in the trade-off between genuine and counterfeit goods: what are the consumers' underlying motives and value-based drivers?', Journal of Brand Management, Vol. 19, No. 7, pp.544-566.

Wiedmann, K-P., Hennigs, N. and Siebels, A. (2007) 'Measuring consumers' luxury value perception: a cross-cultural framework', Academy of Marketing Science Review, Vol. 7, No. 7, pp.1-21.

Wiedmann, K-P., Hennigs, N. and Siebels, A. (2009) 'Value-based segmentation of luxury consumption behaviour', Psychology \& Marketing, Vol. 26, No. 7, pp.625-651.

Wilkie, W.L. (1994) Consumer Behaviour, 3rd ed., John Wiley \& Son, Inc., New York.

Yoo, B. and Lee, S-H. (2009) 'Buy genuine luxury fashion products or counterfeits?', Advances in Consumer Research, Vol. 36, pp.280-286.

Zaichkowsky, J.L. (1985) 'Measuring the involvement construct', Journal of Consumer Research, Vol. 12, No. 3, pp.341-352.

Zinkhan, G.M. and Karande, K.W. (1991) 'Cultural and gender differences in risk-taking behaviour among American and Spanish decision makers', The Journal of Social Psychology, Vol. 131, No. 5, pp.741-742. 